\title{
Neurogenic Shock
}

\author{
Elizabeth H. Mack ${ }^{*}$
}

\author{
Division of Pediatric Critical Care Medicine, Palmetto Health Children's Hospital, 9 Medical Park, Suite 530, \\ Columbia, SC 29203, USA
}

\begin{abstract}
Neurogenic shock is a type of distributive shock that describes the sudden loss of autonomic tone due to spinal cord injury often characterized by hypotension and relative bradycardia. Loss of sympathetic tone occurs with injuries above T6 and results in decreased systemic vascular resistance. Peripheral vasoconstrictors, chronotropes, and inotropes may be needed in cases of neurogenic shock. Autonomic instability may develop and often persists several weeks after the injury. Aggressive management is imperative in the initial phases of neurogenic shock to avoid further secondary ischemic injury to the cord.
\end{abstract}

Keywords: Spinal cord injury, shock, autonomic dysreflexia.

\section{INTRODUCTION}

Neurogenic shock describes the sudden loss of autonomic tone due to spinal cord injury (SCI). Disruption of the descending sympathetic pathways results in unopposed vagal tone in the vascular smooth muscle, causing decreased systemic vascular resistance and vasodilation. The hypotension that results from neurogenic shock places patients at increased risk of secondary spinal cord ischemia due to impairment of autoregulation [1-3]. Though the terms are sometimes used interchangeably, neurogenic shock describes the hemodynamic changes following SCI, whereas spinal shock is characterized by a reversible reduction of sensory, motor, or reflex function of the spinal cord below the level of injury [4].

Our search strategy involved a PubMed search from 1986 to 2012 of articles using the search term "neurogenic shock" in the English language. Many articles were excluded due to irrelevance to the topic and scope of this discussion. Also references from these articles were scanned and relevant articles included. Articles involving both adults and children were utilized, and select animal studies were included.

\section{CLINICAL MANIFESTATIONS}

Neurogenic shock is a type of distributive shock, but should be a diagnosis of exclusion in the early phases of traumatic resuscitation after hemorrhagic shock is ruled out. There is no definitive diagnostic test, but classically patients exhibit hypotension and relative bradycardia. The bradycardia is often exacerbated by suctioning, defecation, turning, and hypoxia [5]. The skin is often warm and flushed initially. Hypothermia may develop because of profound vasodilation and heat loss. Often the central venous pressure is low due to decreased systemic vascular resistance. An

*Address correspondence to this author at the Division of Pediatric Critical Care Medicine, Palmetto Health Children's Hospital, 9 Medical Park, Suite 530, Columbia, SC 29203, USA; Tel: (803) 434-4603; Fax: (803) 434-3866; E-mail: ElizabethH.Mack@palmettohealth.org animal model of complete cervical SCI demonstrated bradycardia and hypotension, increased cardiac output due to increased stroke volume, and an increase in serum vasopressin [6]. There is some evidence to suggest that hypertension occurs within the first few minutes of SCI, often in the field or emergency department, and hypotension may follow later [7-9]. Thus, patients with SCI must be monitored closely for the development of neurogenic shock even if it is not present on presentation. The joint committee of the American Spinal Injury Association and the International Spinal Cord Society proposed a set of definitions of general autonomic nervous system dysfunction (neurogenic shock, orthostatic hypotension, autonomic dysreflexia, temperature dysregulation, sweating disturbances) following adult SCI that should be assessed by clinicians [10].

\section{EPIDEMIOLOGY}

Pediatric SCI occurs in 1.99 per 100, 000 children in the United States, and new cases account for approximately 1,500 annual hospital admissions [11]. The most common (41-56\%) cause of traumatic pediatric SCI is motor vehicle crashes, and $67 \%$ of these patients are not properly restrained [11-13]. Other causes of SCI include spinal anesthesia, Guillain-Barre syndrome, other neuropathies, and autonomic nervous system toxins. Causes of SCI unique to the pediatric population include birth-related injuries, lap-belt injuries, transverse myelitis, and child abuse. Also, cervical subluxation may result in cervical SCI in children with Trisomy 21, juvenile idiopathic arthritis, skeletal dysplasias, and tonsillopharyngitis [14-16]. Cervical SCI is more common in children than in adults, presumably due to the anatomical features distinguishing these populations including larger head size and underdeveloped neck muscles in children. Cervical SCI has an overall mortality of $18-27 \%$ in children $[12,13]$.

Spinal cord injury without radiographic abnormality (SCIWORA) and spinal cord injury without evidence of radiographic trauma (SCIWORET) are terms introduced 
before imaging modalities were sophisticated enough to reveal evidence of trauma that we now are able to see using magnetic resonance imaging (MRI). SCIWORET is a term more commonly used in adult trauma because of pre-existing conditions such as spinal stenosis and disc herniation. A 2001 article reported that SCIWORA occurs in $38 \%$ of children with cervical SCI, and is common in sporting injuries and in victims of child abuse [12]. This incidence is likely decreasing as MRI technology advances.

The loss of sympathetic tone, and thus neurogenic shock, is most common when the level of the injury is above T6 [8]. Moreover, neurogenic shock may occur anytime after the onset of injury or illness, ranging from the time of presentation to several weeks after presentation. No human studies document the hemodynamic changes occurring after acute SCI in children, and the incidence of neurogenic shock in children with SCI is unknown. However, reports indicate anywhere from $50-90 \%$ of adults with cervical SCI require fluid resuscitation and vasoactive infusions to achieve the adult parameters recommended (MAP $>85-90 \mathrm{~mm} \mathrm{Hg}$ for 7 days) by the Congress of Neurological Surgeons' guidelines for management of SCI [5, 8, 17-20]. Adults with higher SCI (C1-C5) may be more likely to require cardiovascular interventions, such as vasoactive agents or cardiac pacing, than lower (C6-C7) SCI [21].

\section{MANAGEMENT}

Decreased systemic vascular resistance results in a relative hypovolemia due to increased venous capacity, and isotonic fluid administration is often necessary. However, hypotension due to neurogenic shock is often refractory to fluid resuscitation. Nevertheless, hypotension in a trauma patient cannot be assumed to be due to neurogenic shock initially, and could be a sign of hemorrhagic shock. Thus, trauma victims with hypotension should be treated initially with crystalloid $(0.9 \%$ sodium chloride, ringer's lactate) or colloid (albumin, blood products) fluids and evaluated for any ongoing blood loss. Patients should be adequately resuscitated from a hemodynamic perspective before undergoing operative spinal cord decompression.

Hypotension must be treated immediately in order to avoid secondary ischemic SCI. Cervical SCI is often seen in patients who also have traumatic brain injury and hypotension cannot be tolerated in the setting of traumatic brain injury either. Mannitol should be avoided if shock is present in patients with suspected traumatic brain and spinal cord injury, as hypertonic saline is now recommended as first-line osmotherapy agent in pediatric severe traumatic brain injury [22].

If hypotensive patients have normal chronotropy and inotropy, then an $\alpha_{1}$ agonist acting as a peripheral vasoconstrictor such as phenylephrine is indicated. Norepinephrine may also be considered, as it has $\alpha_{1}$ and $\beta_{1}$ agonistic activity [23]. Epinephrine and vasopressin infusions may be used in refractory cases of hypotension [23]. The evidence for the elevated MAP goal (MAP $>85-90$ $\mathrm{mm} \mathrm{Hg}$ for 7 days) in adults published by the Congress of Neurological Surgeons is weak [24]. Of course, the definition of hypotension in children (systolic blood pressure
$<70 \mathrm{~mm} \mathrm{Hg}$ plus twice the age in years) is appropriate to consider when preventing and treating shock in general in children, but in the case of SCI the blood pressure should probably be maintained higher than the minimum acceptable blood pressure; the blood pressure goals in pediatric patients with SCI are unknown [20].

If bradycardia is present, patients may respond to atropine, glycopyrrolate, or vasoactive infusions with chronotropic, vasoconstrictor, and inotropic properties such as dopamine or norepinephrine. Also, isoproterenol may be considered if a strictly chronotropic agent is needed.

Phenylephrine can potentially cause reflex bradycardia, as there is no $\beta$ agonist activity, and should be used with caution in patients with bradycardia as part of their neurogenic shock presentation. In rare cases, cardiac pacing has been successful however since the cause of the bradycardia is neurochemical rather than electrophysiological, it may be more prudent to use pharmacological treatments. If patients demonstrate particular sensitivity to suctioning or positioning, one may consider giving atropine or glycopyrrolate prior to manipulation. Methylxanthines (theophylline, aminophylline) and propantheline have also been used for refractory bradycardia [25-29]. Sinus bradycardia is most common in patients with severe cervical SCI, but patients may develop other dysrhythmias, including AV block, atrial fibrillation, or even cardiac arrest [5].

\section{PROGNOSIS}

Patients with cervical SCI are more likely to develop neurogenic shock $[5,8,19,30]$. In fact, patients with thoracolumbar SCI do not commonly develop neurogenic shock [5]. Likewise, complete injuries and higher grade injuries according to the American Spinal Injury Association grade often lead to more severe neurogenic shock $[5,19,24$, 30-32]. Presence of neurogenic shock has been shown to lead to delays in operative management, which may potentially worsen outcome as well [30]. Though it is recommended to avoid and aggressively treat hypotension, it is unknown whether hypotension worsens outcome [33].

Neurogenic shock can persist for 1-6 weeks after the injury $[3,5,24]$. Autonomic dysreflexia, low resting blood pressure, and orthostatic hypotension are not uncommon during the chronic phase, often after neurogenic shock has resolved [1, 2, 34, 35]. Autonomic instability is often manifested by episodic hypertension, flushing, diaphoresis, and tachycardia.

In conclusion, spinal cord injury regardless of mechanism may result in neurogenic shock characterized by sudden loss of autonomic tone resulting in hypotension and relative bradycardia. Higher lesions are associated with more severe deficits. Peripheral vasoconstrictors, chronotropes, and inotropes may be needed in cases of neurogenic shock. The hypotension that results from loss of autonomic tone can precipitate further secondary ischemic injury to the spinal cord, and should be managed aggressively. Dysautonomia may develop and often persists several weeks after the injury. Any patient presenting with the possibility of SCI should have their spine immobilized as soon as is practical to prevent any further injury to or compression on the spinal cord. 


\section{CONFLICT OF INTEREST}

The authors confirm that this article content has no conflicts of interest.

\section{ACKNOWLEDGEMENTS}

Declared none.

\section{REFERENCES}

[1] Krassioukov A, Claydon VE. The clinical problems in cardiovascular control following spinal cord injury: an overview. Prog Brain Res 2006; 152: 223-9.

[2] Bravo G, Gui'zar-Sahagu'n G, Ibarra A, Centurio'n D, Villalo'n CM. Cardiovascular alterations after spinal cord injury: an overview. Curr Med Chem Cardiovasc Hematol Agents 2004; 2: $133-48$.

[3] Furlan JC, Fehlings MG. Cardiovascular complications after acute spinal cord injury: pathophysiology, diagnosis, and management. Neurosurg Focus 2008; 25(5): 1-15.

[4] Ditunno JF, Little JW, Tessler A, Burns AS. Spinal shock revisited: a four-phase model. Spinal Cord 2004; 42: 383-95.

[5] Lehmann KG, Lane LG, Piepmeier JM, Batsford WP. Cardiovascular abnormalities accompanying acute spinal cord injury in humans: incidence, time course and severity. J Am Coll Cardiol 1987; 10(1): 46-52.

[6] Zahra M, Samdani A, Piggott K, et al. Acute changes in systemic hemodynamics and serum vasopressin after complete cervical spinal cord injury in piglets. Neurocrit Care 2010; 13: 132-40.

[7] Zipnick RI, Scalea TM, Trooskin SZ, et al. Hemodynamic responses to penetrating spinal cord injuries. J Trauma 1993; 35(4): $578-82$.

[8] Guly HR, Bouamra O, Lecky FE. The incidence of neurogenic shock in patients with isolated spinal cord injury in the emergency department. Resuscitation 2008; 76: 57-62.

[9] Krassioukov AV, Karlsson AK, Wecht JM, Wuermser LA, Mathias CJ, Marino RJ. Assessment of autonomic dysfunction following spinal cord injury: rationale for additions to International Standards for Neurological Assessment. J Rehabil Res Dev 2000; 44: 103-12.

[10] Popa C, Popa F, Grigorean VT, et al. Vascular dysfunctions following spinal cord injury. J Med Life 2010; 3(3): 275-85.

[11] Vitale MG, Goss JM, Matsumoto H, Roye DP Jr. Epidemiology of pediatric spinal cord injury in the United States: years 1997 and 2000. J Pediatr Orthop 2006; 26(6): 745-9.

[12] Brown RL, Brunn MA, Garcia VF. Cervical spinal cord injuries in children: a review of 103 patients treated consecutively at a level one pediatric trauma center. J Pediatr Surg 2001; 36(8): 1107-14.

[13] Platzer P, Jaindl M, Thalhammer G, Dittrich S, Kutscha-Lissberg F, Vecsei V, Gaebler C. Cervical spine injuries in pediatric patients. J Trauma 2007; 62(2): 389-96.

[14] Dunne K, Hopkins IJ, Shield LK. Acute transverse myelopathy of childhood. Dev Med Child Neurol 1986; 28: 198-204.

[15] Knebusch M, Strassburg HM, Reiners K. Acute transverse myelitis in childhood: nine cases and review of the literature. Dev Med Child Neurol 1998; 40: 631-9.

[16] American Academy of Pediatrics. Committee on Sports Medicine. Atlantoaxial instability in Down syndrome. Pediatrics 1984; 74: $152-4$.

[17] Congress of Neurological Surgeons. Guidelines for the management of acute cervical spine and spinal cord injuries. Neurosurgery 2002; 50: S1-198.
[18] Levi L, Wolf A, Belzberg H. Hemodynamic parameters in patients with acute cervical cord trauma: description, intervention, and prediction of outcome. Neurosurgery 1993; 33(6):1007-17.

[19] Vale FL, Burns J, Jackson AB, Hadley MN. Combined medical and surgical treatment after acute spinal cord injury: results of a prospective pilot study to assess the merits of aggressive medical resuscitation and blood pressure management. J Neurosurg 1997; 87: $239-46$

[20] Mallek JT, Inaba K, Branco BC, et al. The incidence of neurogenic shock after spinal cord injury in patients admitted to a high-volume level I trauma center. Am Surg 2012; 78: 623-6.

[21] Bilello JF, Davis JW, Cunningham MA, Groom TF, Lemaster D, Sue LP. Cervical spinal cord injury and the need for cardiovascular intervention. Arch Surg 2003; 138: 1127-9.

[22] Kochanek PM, Carney N, Adelson PD, et al. Guidelines for the acute medical management of severe traumatic brain injury in infants, children, and adolescents--second edition. Pediatr Crit Care Med 2012; 13 (Suppl 1): S1-82

[23] Stratman RC, Wiesner AM, Smith KM, Cook AM. Hemodynamic management after spinal cord injury. Orthopedics 2008; 31(3): 252-5.

[24] Casha S, Christie S. A Systematic Review of Intensive Cardiopulmonary Management after Spinal Cord Injury. J Neurotrauma 2010; 27: 1-17.

[25] Pasnoori VR. Leesar MA. Use of aminophylline in the treatment of severe symptomatic bradycardia resistant to atropine. Cardiol Rev 2004; $12(2): 65-8$

[26] Sakamoto T. Sadanaga T. Okazaki T. Sequential use of aminophylline and theophylline for the treatment of atropineresistant bradycardia after spinal cord injury; a case report. J Cardiol 2007; 49: 91-6.

[27] Schulz-Stubner S. The use of small-dose theophylline for the treatment of bradycardia in patients with spinal cord injury. Anesth Analg 2005; 101: 1809-11.

[28] Weant KA, Kilpatrick M, Jaikumat S. Aminophylline for the treatment of symptomatic bradycardia and asystole secondary to cervical spine injury. Neurocrit Care 2007; 7: 250-2.

[29] Whitman CB, Schroeder WS, Ploch PJ, Raghavendran K. Efficacy of aminophylline for treatment of recurrent symptomatic bradycardia after spinal cord injury. Pharmacotherapy 2008; 28(1): $131-5$.

[30] Tuli S, Tuli J, Coleman WP, Geisler FH, Krassioukov A. Hemodynamic parameters and timing of surgical decompression in acute cervical spinal cord injury. J Spinal Cord Med 2007; 30: 48290.

[31] ASIA classification. Available at http://www.asia-spinalinjury.org/ elearning/ISNCSCI_Exam Sheet r4.pdf [Accessed on December $16,2012]$.

[32] ASIA autonomic standards assessment. Available at http://www. asia-spinalinjury.org/elearning/Autonomic Standards Assessment _Form_FINAL_2009.pdf [Accessed on December 16, 2012].

[33] Chesnut RM, Gautille T, Blunt BA, Klauber MR, Marshall LF. Neurogenic hypotension in patients with severe head injuries. J Trauma 1998; 44: 958-63.

[34] McMahon D, Tutt M, Cook AM. Pharmacological management of hemodynamic complications following spinal cord injury. Orthopedics 2009; 32(5): 331 .

[35] Vogel CL, Anderson CJ. Spinal cord injuries in children and adolescents: A review. J Spinal Cord Med 2003; 26:193-203. 